\title{
A METAFÍSICA COMO A ESSÊNCIA DO HOMEM EM HEIDEGGER
}

\author{
The metaphysics as the essence of man in Heidegger
}

Daniel Schiochett

UFSC

Resumo: A questão aqui levantada se move em dois polos implicados mutuamente a partir do círculo hermenêutico heideggeriano: metafísica e homem. O primeiro momento do texto consiste em apontar como Heidegger opera a desconstrução da metafísica com o objetivo de mostrar que a metafísica não é simplesmente uma disciplina entre outras da filosofia, mas um acontecimento essencial do ser-aí humano. O segundo momento pretende definir a partir de que experiência fundamental do ente humano nasce a metafísica. Ser e tempo e, principalmente, Que é Metafísica, servirão de guia para o presente texto.

Palavras-chave: metafísica, desconstrução, homem, angústia.

Abstract: The question presented here originates from the two mutually implied poles of the hermeneutical circle of Heidegger: metaphysics and Man. The first part of this paper discusses metaphysics by showing how Heidegger accomplishes the deconstruction of the metaphysical with the intention of showing that the metaphysical is not simply a discipline like others in philosophy but an essential experience of the human Dasein. The second half intends to define the metaphysical as being born from the fundamental experience of the human being. Being and Time and, principally, What is Metaphysics? will serve as a guide for the present paper.

Keywords: metaphysics, deconstruction, man, anguish.

\section{Introdução}

Heidegger, ao ir ao fundamento do pensamento metafísico pretende enxergar por entre a penumbra de quase vinte e cinco séculos de especulação metafísica sobre a experiência essencial do homem. Essa disciplina, por carregar algo de tão essencial em sua constituição, a saber, a resposta do ente humano diante do assombro da existência, logo requisita para si a autoridade de fundamentar as outras experiências humanas, modos do homem ser no mundo. Por este motivo, a metafísica se mostrou 
como o discurso que historicamente propôs o fundamento das coisas, sejam elas: a relação entre os homens (a ética e a política); o conhecimento seguro (a filosofia e a ciência); o sentido do mundo (a arte e a religião), etc. Ou seja, se preocupou em dizer, afinal, o que é homem, mas de forma cindida, perdido em meio ao ente. Nesse turbilhão de interpretações, a metafísica esqueceu que seu nascimento está condicionado à experiência do homem enquanto existência que pergunta pelo ser.

Heidegger acredita ser possível revelar a constituição essencial do homem ocultada pela própria metafísica. Todavia, isso não pode ser feito recorrendo a um expediente exterior à determinação metafísica da própria essência do homem. Qualquer solução supostamente exterior à metafísica corre o risco de ser ingênua por não perceber que também nascera das entranhas da metafísica ocidental. Revelar a essência do homem só é possível na medida em que a própria metafísica seja desconstruída. Sob os escombros metafísicos, a essência do homem aparece não como algo preexistente à metafísica e à história ocidental, mas como essência que se escolhe no próprio fazer metafísico.

Este texto não tem profundas ambições. Pretende convidar o leitor a prestar atenção à relação profunda que existe entre a metáfísica e o homem, tal como Heidegger entende estas noções. Por isso, o primeiro momento do texto apresentará a etapa destrutiva da análise heideggeriana e pretende responder o que é a metafísica. 0 segundo momento do texto apresentará a etapa construtiva, por assim dizer, e pretende responder o que é o homem.

\section{A metafísica: terreno para determinação da essência do homem}

O estudo do da tradição ocidental tem um papel importante para Heidegger. Não serão as disciplinas ônticas que dirão quem é o homem. Para Heidegger, estas disciplinas já são desdobramentos de decisões metafísicas e, por isso, é necessário mergulhar na própria metafísica a fim de dizer qual é a essência do homem. Mas a metafísica é essencialmente o terreno em que se desenvolveu a nossa compreensão do 
ser em geral e não apenas do ser do homem. Como entender, então, a frase do filósofo que afirma que "qualquer doutrina do ser é já em si mesma uma doutrina sobre a essência do homem"1 ? Este é o papel da desconstrução da metafísica operada por Heidegger. Heidegger busca na tradição que se pergunta pelo ser as raízes da nossa própria compreensão de homem. Se a metafísica, ao pensar o ser também pensa o homem, a desconstrução daquela abre possibilidades de compreender o homem mais originariamente. A destruição heideggeriana tem o objetivo de remover, ou melhor, repensar os pressupostos que usamos toda vez que nos perguntamos pelo homem.

De que forma Heidegger opera essa destruição?

Caso a questão do ser deva adquirir a transparência de sua própria história, é necessário, então, que se abale a rigidez e o endurecimento de uma tradição petrificada e se removam os entulhos acumulados. Entendemos essa tarefa como destruição do acervo da antiga ontologia, legado pela tradição. Deve-se realizar essa destruição seguindo-se o fio condutor da questão do ser até se chegar às experiências originárias em que foram obtidas as primeiras determinações do ser que, desde então, tornaram-se decisivas. ${ }^{2}$

A destruição, ou desconstrução como sugere $\operatorname{Stein}^{3}$, é prefigurada já em Ser e tempo. Uma remoção de entulhos e uma refundação da história da filosofia se fazem necessários seguindo um fio condutor. Fio condutor este que é a questão do ser,

\footnotetext{
${ }^{1}$ HEIDEGGER, M. Was heisst Denken? apud HAAR, M. Heidegger e a essência do homem. Lisboa: Instituto ${ }^{2}$ HEIDEGGER, M. Ser e tempo. v. 1. 14. ed. Petrópolis: Vozes, 2005. p. 51

${ }^{3}$ A opção pelo termo desconstrução ao invés de destruição não é de todo pacífica. À parte da discussão acerca do que seria mais adequado, parece-nos bastante interessante tal opção. Além de comentadores como Stein (Cf.: STEIN, E. Diferença e metafísica: ensaios sobre a desconstrução. Porto Alegre: EDIPUCRS, 2000), autores consagrados influenciados pelo pensamento de Heidegger também subvertem a letra do filósofo alemão a fim de manter a essência do seu conceito. Talvez seja por isso que Derrida faça justamente da noção de desconstrução o carro chefe da sua crítica à metafísica (Cf.: DERRIDA, J. Margens da Filosofia. Campinas: Papirus, 1991). Mas isso só é possível na medida em que a própria noção de destruição em Heidegger guarda um significado positivo. Heidegger efetivamente não destrói a tradição, mas retira camadas de sedimentos e "construções metafísicas" que foram sendo depositadas uma sobre as outras através da história. O trabalho de Heidegger consiste em expor os fundamentos de cada camada e para isso não pode simplesmente "implodir" a tradição. Ele precisa escavá-la em busca de seus fundamentos. Por isso, a destruição operada por Heidegger não é, de modo algum, um "pôr abaixo" a metafísica: "a destruição também não tem o sentido negativo de arrasar a tradição ontológica. Ao contrário, ela deve definir e circunscrever a tradição em suas possibilidades positivas e isto quer sempre dizer em seus limites [...]. Negativamente, a destruição não se refere ao passado; a sua crítica volta-se para o "hoje" e os modos vigentes de se tratar a história da ontologia [...]. Em todo caso, a tradição não se propõe a sepultar o passado em um nada negativo, tendo uma intenção positiva" (HEIDEGGER, M. Ser $e$ Tempo, p. 51).
} 
percebida pela metafísica, mas ocultada. Assim, o primeiro passo da pesquisa heideggeriana passa necessariamente por uma remoção de entulhos, pela redução, termo comum à fenomenologia, dos conceitos filosófico-ontológicos à existência do ente que nós mesmos somos, isto é, ao Dasein. Estes entulhos são justamente os préconceitos com que o homem questiona seu próprio ser. A redução, nesse sentido, prepararia a desconstrução, na medida em que reconduziria o homem à experiência originária de seu ser como ser-no-mundo cujo sentido se daria na temporalidade.

Numa outra perspectiva, a desconstrução consistiria numa reinterpretação da história da metafísica, mostrando em que sentido o ser ficou esquecido em tal pensamento. Interessante notar o sentido hermenêutico dado por Heidegger a esse movimento de ir à tradição, de se apropriar do texto, da história com vistas à experiência originária que os gerou. Experiência originária esta que se revela a partir da análise do fio condutor, a questão do ser, descoberta pela redução e assumida de forma ainda mais radical na desconstrução. Esta radicalidade, segundo Stein, é percebida no caráter arbitrário e violento da interpretação heideggeriana ${ }^{4}$. Cabe ao filósofo arrancar da metafísica o ser que se encontra esquecido. Visto que o objetivo do filósofo é mostrar onde o ser, como condição de possibilidade da metafísica, ficou esquecido pela tradição, ele precisa empreender uma desconstrução que violenta o texto. A finalidade dessa desconstrução é arrancar o conceito de ser que aí se esconde e que serviu como pressuposto do pensamento interpretado e que impulsiona a cada vez o questionamento.

Mas por que, para Heidegger, na metafísica o ser se mostra como a possibilidade, todavia oculta? O ser se mostra como possibilidade oculta porque a metafísica pensa o seu objeto a partir de um ponto de vista universal e neutro. De fato, para o filósofo: "metafísica é o perguntar além do ente para recuperá-lo, enquanto tal para a compreensão" ${ }^{5}$. Metafísica, desse modo, já fica caracterizada não como uma disciplina filosófica, mas antes como uma atitude, um modo de ser daquele que

\footnotetext{
${ }^{4}$ Cf.: STEIN, E. Diferença e metafísica: ensaios sobre a desconstrução, p. 31.

${ }^{5}$ HEIDEGGER, M. Que é metafísica. In:___. Conferências e escritos. São Paulo: Abril Cultural. 1979. p. 43.

330 | Pensando - Revista de Filosofia Vol. 6, № 11, $2015 \quad$ ISSN 2178-843X
}


pergunta, na medida em que "metafísica é o perguntar (...)", e quem pergunta somos nós a partir de nosso ser-no-mundo situado e datado. Com isso não podemos pretender universalidade. Em segundo lugar, metafísica é a atitude daquele que pergunta além do ente. Ou seja, é um modo de ser que, partindo do ente, se coloca para além dele, num salto, ou ainda, numa escolha livre e sem fundamento. Novamente, a objetividade não é alcançada, e nem poderia, na medida em que é uma pretensão baseada na decisão e na escolha ou ainda no sustentar ${ }^{6}$.

Desse modo, o impulso metafísico se ampara numa livre decisão do Dasein de sustentar sua existência, de dar uma resposta ao ser. Mas por que, então, a metafísica, para Heidegger esquece o ser? O homem esquece esse seu sem fundamento aberto e livre porque se decide em favor de um fundamento já posto antecipadamente, ou ainda, recuperado conforme uma compreensão já dada historicamente. Lembremos que a metafísica é também uma tentativa de recuperar o ente para a compreensão. Ao recuperar o ente em sua totalidade para a compreensão acontece o que podemos designar entificação do ser, isto é, colocamos o ser num padrão já estabelecido de objetividade. Assim, na idéia de que a metafísica pergunta pelo ente para recuperá-lo para a compreensão já vem explicitada a tese básica acerca do que Heidegger entende quando fala em metafísica. Para Heidegger, a metafísica investiga o ente como tal, tem sua investigação orientada pelo ser do ente, mas não se propõe a questão do ser:

Não obstante, se pensarmos a "questão do Ser" no sentido da questão sobre o Ser, como tal, será então claro para todo aquele que a pensar também, que à questão metafísica o Ser, COMO TAL, fica oculto, permanece-lhe esquecido e de modo tão decisivo, que o próprio esquecimento do ser, que é novamente

\footnotetext{
${ }^{6}$ Cf.: HEIDEGGER, M. Que é metafísica, p. 59. Os conceitos de decisão e escolha fazem referência às noções de existência e liberdade, modos de ser do Dasein. "A palavra [existência] designa um modo de ser e, sem dúvida, do ser daquele ente que está aberto para a abertura do ser, na qual se situa enquanto a sustenta" (HEIDEGGER, M. Que é metafísica, 1979, p. 59). Assim, quando Heidegger fala que a essência do Dasein é a existência, significa antes de tudo que o mais próprio deste ser é a abertura, é a possibilidade de deixar vir a si os entes a partir de uma compreensão do ser (Cf.: HEIDEGGER, M. Sobre a essência da verdade. In:__. Conferências e escritos. São Paulo: Abril Cultural, 1979. p. 138). Todavia, não apenas o Dasein se situa nessa compreensão de ser, mas também a sustenta, se decide por ela dando uma resposta (Cf.: HEIDEGGER, Question I apud HAAR, M. Heidegger e a essência do homem, p. 102).
} 
esquecido, constitui o impulso desconhecido mas constante da investigação metafísica. $^{7}$

Com isso, confirmamos em Heidegger o que já vínhamos dizendo, isto é, que a metafísica deixa oculta a questão do ser. E a deixa oculta porque a confunde com a questão sobre o ser, isto é, pensa que o ser possa ser questionado por sobre, além de si mesmo. Isto significa também dizer em si mesmo, a partir de um ponto de vista universal que garanta a objetividade da resposta. Esse é o modo de investigar o ente e o modo como a metafísica representa o ser. Mas, acrescenta Heidegger, é esse próprio ocultamento do ser operado pelo questionar objetivista da metafísica que constitui o impulso desconhecido da própria metafísica. Uma pergunta que nunca é respondida, sempre continua sendo perguntada.

Todavia, por que esse impulso desconhecido nutre a investigação sem ser questionado? Porque a questão do ser mesmo não tem como ser investigada a partir da perspectiva metafísica que busca a recuperação, a adequação do ser a uma racionalidade. Mas, como "em toda parte se iluminou o ser, quando a metafísica representa o ente" ${ }^{\prime 8}$, é a própria metafísica, ou melhor, sua desconstrução, a possibilidade de colocar de maneira mais radical a questão do ser e, assim, a questão do homem. Somente colocando a questão do homem de maneira radical Heidegger pode criticar a noção de sujeito e animal racional e pensar o homem originalmente a partir da relação com o ser.

Quanto ao modo da investigação da metafísica, Heidegger assinala uma peculiaridade. Para o filósofo, "toda questão metafísica somente pode ser formulada de tal modo que aquele que interroga, enquanto tal, esteja implicado na questão, isto é, seja problematizado" ${ }^{\prime 9}$. O sentido do questionar não está numa possível resposta, mas antes na pergunta que revela uma atitude, uma disposição daquele que interroga. Isso mostra que a nossa digressão acerca da desconstrução da noção de metafísica está

\footnotetext{
${ }^{7}$ HEIDEGGER, M. Introdução à metafísica. Rio de Janeiro: Tempo Brasileiro, 1969. p. 49.

${ }^{8}$ HEIDEGGER, M. Introdução à metafísica, p. 55.

${ }^{9}$ HEIDEGGER, M. Que é metafísica, p. 35.
} 
ligada intimamente àquilo que no início nos propomos, qual seja, dizer que a metafísica é um acontecimento no âmbito do ser-aí humano na medida em que o homem interroga para além e apesar da physis, dos entes, da natureza, em direção ao ser. A questão fundamental que interroga a metafísica põe o próprio homem, enquanto aquele que interroga, em questão.

\section{O homem: fundador da metafísica}

Por carregar a característica daquele que interroga, a pergunta metafísica que questiona o fundamento do ente é marcada pelo ser-no-mundo, pela finitude. Afirma Heidegger: "Somente no nada do ser-aí o ente em sua totalidade chega a si mesmo, conforme sua mais própria possibilidade, isto é, de modo finito" ${ }^{10}$. O homem, enquanto existente, pode questionar o ente porque este já é dessa ou daquela maneira, já faz parte do mundo do Dasein.

Por perguntar sobre o ser e fazer uso da metafísica, o modo de análise e o tema da investigação heideggeriana mostram que o filósofo não nega a metafísica, mas pensa colocá-la em seu devido lugar: dentro da finitude humana. Só ali, finitamente, é possível fazer metafísica, visto que, como dissemos, ela é um "acontecimento essencial do ser-aí humano".

De fato, para Heidegger, o Dasein sustenta e é sustentado pela existência. Ela mesma não é uma coisa que possa ser objetivada, não é anterior, nem posterior, nem interior, nem exterior. Mas se não fosse por ela não seríamos como somos. O ser mesmo, como dissemos, não é uma coisa. Nada que podemos falar dele é real, mas se não há ser, se não há sentido, toda palavra some e nosso questionamento sequer teria começado.

Mas o fazemos porque sustentamos a palavra. Sustentamos a metafísica. Sustentamos nossa essência de modo a nos compreender como entes humanos. A discussão acerca da desconstrução da metafísica pretende mostrar que o fundamento dela mesma é o Dasein humano. Mas o que acontece nesse ente de tão especial a ponto

${ }^{10}$ HEIDEGGER, M. Que é metafísica, p. 43-4. 
de ele ser o fundamento da metafísica? O que acontece em nós a ponto de nos pensarmos como humanos? Ou ainda, por que o homem se entende como homem, como animal racional ou sujeito pensante? É a noção heideggeriana do homem angustiado com seu ser-no-mundo que nos permite entender como, em Heidegger, a metafísica é "produto", resposta do ente que põe o fundamento a si e às coisas, sustentando a metafísica.

O homem, para Heidegger, somente pode ser o fundamento da metafísica e assim fazer metafísica porque nele há uma pré-compreensão do ser. A todo momento somos impelidos a dizer: "este carro é azul", "o computador está com problemas", "a política é lugar da liberdade", etc. Todavia, mesmo contando com o ser, compreendendo-o pré-tematicamente, muito poucas vezes somos tomados pela sensação aterradora e deslumbrante de que somos, de que as coisas são, enfim, de que há ser, mas que poderia não haver. É o instante da angústia, o momento do "nadificar do nada" ${ }^{11}$. Nessa hora fazemos, segundo o filósofo, a pergunta fundamental da metafísica:

\begin{abstract}
Assim num júbilo da alma, quando as coisas se transfiguram e nos parecem rodear pela primeira vez, como se antes nos fosse possível perceber-lhes a ausência do que a presença e essência. Assim, numa monotonia, quando igualmente distamos de júbilo e desespero e a banalidade do ente estende um vazio, onde se nos afigura indiferente, se há o ente ou se não há, o que faz ecoar de forma especial a questão: Por que há simplesmente o ente e não antes o Nada? ${ }^{12}$
\end{abstract}

Essa disposição, esse "sentimento" é o que, em dada medida, a filosofia antiga chamou de thauma. Nesse instante o homem "sente" seu ser, mas isso não acontece "dentro" dele, acontece nele como ser-no-mundo, já sempre fora de si mesmo. Por isso Heidegger chama esse sentimento de disposição ou humor. De fato, para Heidegger, existem alguns humores ou disposições que colocam o homem cruamente diante da existência. Mas isso só é possível, como dissemos, porque esse "sentimento não é algo que se localiza no 'interior'; o sentimento é aquele modo básico de nosso Dasein em virtude do qual e de acordo com o qual estamos sempre já elevados, acima e

${ }^{11}$ Cf.: HEIDEGGER, M. Que é metafísica, p. 40.

12 HEIDEGGER, M. Introdução à metafísica, p. 33. 
além de nós mesmos, para os entes como um todo tal qual importam, ou não importam, para nós"13.

Assim, dentre alguns humores, como o tédio e a alegria, é a angústia, para o filósofo, que leva o homem a perguntar radicalmente pelo ser, a colocar-se numa atitude para além do ente. "O estar suspenso do ser-aí dentro do nada originado pela angústia escondida é o ultrapassar do ente em sua totalidade: a transcendência" ${ }^{14}$, afirma o filósofo. Falamos: esta ultrapassagem é a transcendência. Notemos que, para Heidegger, não se transcende para outra esfera. A angústia originada pela experiência do nada ultrapassa o ente, de onde o homem inautenticamente se compreende, e o coloca diante de seu próprio transcender. Tal transcender não tem como fundamento ente algum, isto é, nada o fundamenta e, por isso, dizemos sem fundamento. Dessa maneira, a angústia leva o homem a se colocar diante do ser não como algo dado, mas como uma possibilidade. Ou ainda, ela é a disposição que revela a possibilidade da impossibilidade da existência. Ela coloca o homem diante da finitude. Por isso ela é uma disposição, é um modo próprio do ser-aí humano de experimentar fundamentalmente o seu sem fundamento ${ }^{15}$.

A angústia se mostra como a disposição que coloca o homem diante de sua existência, cujo sentido último não é dado por nenhum ente. Todo sentido, toda razão, todo fundamento na angústia foge. "Na angústia o ente em sua totalidade se torna caduco" $^{16}$. Por mais que o homem ofereça razões e fundamentos para os entes e assim faça ciência e filosofia, estas erram, revolucionam-se, fracassam, põem novas respostas. Isto ocorre porque a totalidade não objetivada, o mundo em que o Dasein se move permanece como o âmbito que abre sempre e a cada vez novas possibilidades de objetivação e, desse modo, novas questões não antes pensadas. Por isso Heidegger diz que o ente se torna caduco. Mas se o ente se torna caduco, muda ou deixa de ter

\footnotetext{
${ }^{13}$ INWOOD, M. Dicionário Heidegger. Rio de Janeiro: Jorge Zahar, 2002. p. 7.

${ }^{14}$ HEIDEGGER, M. Que é metafísica, p. 42.

${ }^{15}$ Cf.: HEIDEGGER, M. Que é metafísica, p. 38.

${ }^{16}$ HEIDEGGER, M. Que é metafísica, p. 40.
} 
sentido, o ser insiste na existência. E essa existência sem sentido ôntico angustia o Dasein.

Mas não permanecemos na angústia. Se por um lado "seu hálito palpita sem cessar através do ser-aí"17, por outro, o acontecer da angústia é bastante raro ${ }^{18}$. Isso porque nos refugiamos no seio dos entes, no seio daquilo que a tradição e a história apontam como objetivo e certo.

A desconstrução heideggeriana da metafísica analisa a disposição da angústia, primeiramente, porque ela é uma disposição daquele que se encontra no mundo e, segundo, porque ela pode levar o homem que interroga diante dessa sua experiência fundamental. Desse modo, a angústia não coloca o homem perante um fato objetivo, na medida em que o que causa a angústia não é nenhum ente em particular ${ }^{19}$. Nada fora do homem o leva a tal espanto. O que angustia, na angústia é o ser-no-mundo enquanto tal.

É interessante também frisar o suspender operado pela angústia. Esse ser-nomundo revelado na disposição da angústia, justamente por não ser algo de objetivo, é suspenso no seu sem fundamento. É a angústia que arrebata o ser-aí de sua cotidianidade, "da gente", e nos devolve para o seio do ente, não mais a partir do fundamento do ente, mas a partir do dar-se do ser. Este dar-se lembra que o ser mesmo não é um ente, isto é, não requer para si um fundamento, não quer nada em troca, simplesmente se dá, sem causa primeira, em suspensão. A angústia revela este dar-se. Mesmo tudo escapando na angústia "continua presente o puro ser-aí no estremecimento deste estar suspenso"20 ${ }^{20}$ É este permanecer a razão pela qual a pergunta fundamental da metafísica, porque o ente e não antes nada?, para Heidegger, tem tamanha profundidade.

Esta pergunta, em outras palavras, poderia questionar: por que optamos pelo ente, se antes nada tem sentido? Ou ainda: porque sustentamos nossa existência,

\footnotetext{
${ }^{17}$ HEIDEGGER, M. Que é metafísica, p. 42.

${ }^{18}$ Cf.: HEIDEGGER, M. Que é metafísica, p. 39.

${ }^{19}$ Cf.: HEIDEGGER, M. Que é metafísica, p. 39.

${ }^{20}$ HEIDEGGER, M. Que é metafísica, p. 39.
} 
quando ela não tem fundo algum? E, então: porque fazemos metafísica? Estes questionamentos são entendidos como fundamentais para Heidegger pois, se não há fundamento, por que então não ficamos na angústia e jamais procuramos fundar nosso ser-no-mundo? Ou ainda, por que motivo, baseado em qual fundamento, chegamos a fundar, a desvelar o ente? Essa é a questão fundamental para o filósofo na medida em que pergunta desde o fundamento pelo fundamento. Nesta pergunta se tem em vista que o ente é, todavia estranho, mas o ser que aparece por ela, este simplesmente se dá!

A "resposta" que Heidegger aponta para estes questionamentos, já o mostramos, está no fato de o homem ser quem é precisamente por, sem motivo algum, sem causa ôntica nenhuma, se decidir pelo ser e sustentar sua existência. O próprio fato de colocarmos a questão do porquê levanta esse dado. Mesmo não possuindo fundamento algum, não temos como deixar de perguntar. O porquê, mesmo sem fundamento último ôntico, sempre é posto. É posto porque sustentamos nossa existência e fazemos metafísica, ela mesma, assim, mostrada pela desconstrução, sem fundamento último, já que fundada no Dasein angustiado diante do sem fundo do seu ser-no-mundo. A angústia, para Heidegger, se mostra como um fenômeno privilegiado no âmbito do ser-aí humano. É ela que leva o homem a primeiramente perguntar-se por que desde sempre se decide pelo ente ao invés do nada. E é desta pergunta que nasce a metafísica.

Sendo assim, a metafísica é uma possibilidade própria do Dasein, e como toda possibilidade do Dasein se dá na sua história desde disposições existenciais. A metafísica é uma possibilidade desde a angústia. O problema é quando o Dasein pretende, retrospectivamente, ir de volta à experiência originária enquanto existente desde a metafísica já fundada por ele próprio a partir de tal experiência e por isso encoberta. E isso não acontece somente com a metafísica, enquanto disciplina, mas com toda metafísica, isto é, com toda compreensão que o Dasein tem do mundo.

A metafísica é a história erigida pelo Dasein. E como construção, somente um caminhar para trás na história da própria metafísica, uma des-construção pode mostrar 
em que sentido ela mesma é um produto do homem enquanto aquele que se entendia como "racional", isto é, aquele que fundamenta. "Somente porque podemos perguntar e fundamentar foi entregue à nossa existência o destino do pesquisador ${ }^{\prime 21}$. Nesse sentido, somente enquanto há homem, ser-no-mundo, Dasein, há metafísica e "velamento-desvelamento" do ser. Esse é o modo de existência do Dasein. O Dasein é marcado por essa relação íntima com o ser, está posto nesta abertura.

\section{A metafísica e a essência do homem}

Em Kant e o problema da metafísica, Heidegger afirmara: “a pergunta pela essência da metafísica é a pergunta pela unidade das faculdades fundamentais do 'espírito' humano. A fundamentação kantiana revela o seguinte: fundar a metafísica é igual a perguntar pelo homem, quer dizer, é antropologia" 22 . O percurso empreendido neste texto mostra justamente esse movimento. A metafísica se mostra em sua essência não como uma parte da filosofia mas como disposição essencial do homem diante do drama da sua existência. Falar de metafísica é o mesmo que falar do homem. Por isso, e apenas nesse sentido, desconstruir a metafísica é um passo fundamental na tarefa de uma antropologia enquanto ontologia fundamental.

A metafísica acontece enquanto pensamento fundador da nossa civilização. Por isso é necessário entender nosso presente a partir de um ir para trás, de um regresso por sobre a própria história da metafísica. Este é o movimento de desconstrução empreendido por Heidegger. Este movimento faz parte de todo o projeto do filósofo. Nesse sentido, a desconstrução se mostra como uma radicalização do método fenomenológico fundado na própria existência do ser-aí que mantém seu passado como vigor. A própria tradição, e não apenas os entes, é posta sob o crivo da interpretação operada por Heidegger. Não podia ser diferente. Os entes do mundo, os vários modos de ser com que o homem lida no dia-a-dia, não são modos eternos de o ser apresentar-se. 0

\footnotetext{
${ }^{21}$ HEIDEGGER, M. Que é metafísica, p. 44.

22 HEIDEGGER, M. Kant y el problema de la metafísica. México DF: Fondo de Cultura Económica, 1954, p. 173. (Tradução nossa)
} 
ser, ou melhor, as várias compreensões do ser se dão historicamente. Isto significa que, se entendemos algum ente de determinado modo, é porque existiu uma gênese do conteúdo ontológico deste ente. Assim, a fenomenologia, radicalizada como hermenêutica, interpreta o ente na sua constituição histórica e isto significa entender o ente também em seu ser, a partir da concepção de ser vigente em uma época.

Dessa maneira, ao nos propormos entender de que modo a metafísica é um acontecimento essencial do ser-aí não temos outro caminho a não ser mostrar como Heidegger pensa metafísica e homem a partir das gêneses destes conceitos. A metafísica desde sua origem, para Heidegger, se mostra como um discurso acerca do ser. Discurso este, todavia, orientado pelo ente, preso a categorias ônticas, haja vista não ter concebido uma analítica do ente que faz a metafísica. Isso significa que, para Heidegger, a metafísica, ao colocar em questão o ente e procurar seu fundamento, esqueceu de colocar-se a si mesma em questão enquanto fundada por este ente. Heidegger, ao questionar a metafísica, revela que ela não é uma área do pensamento, mas a condição do pensamento como um todo, isto é, ela é a atitude fundamental do ente humano, uma resposta ao drama da sua existência.

O homem diante de sua existência não tem como se manter suspenso na angústia do sem fundamento do seu mundo. A discussão do fenômeno da angústia mostra que, para Heidegger, o ente metafísico se constrói historicamente desse modo porque é o caminho que ele escolhe pra fugir do nada do seu sem fundamento. Mas nem por isso o homem se constitui como um sujeito pairando no ar. O homem é ser-nomundo. Pensar o homem como ser-no-mundo significa romper a noção sujeito-objeto. Não há distância entre o homem e o mundo. Eles estão co-implicados por meio de uma compreensão de ser. É essa compreensão de ser que permite que o homem fale dos entes do mundo. Essa compreensão do ser que possibilita ao homem ser metafísico, instaurar uma tematização e poder dizer, afinal, o que é a metafísica e o que é o homem. 
Apenas um salto do pensamento, salto que acontece justamente quando se ouve o ser e se the responde ocultando-o ${ }^{23}$, é que nos permite entender, ou melhor, entrever essa relação, a relação entre o homem e o ser. O pensamento é a operação de saltar sobre o abismo da experiência sem fundo, a angústia. O salto é um movimento, uma decisão, um ato de liberdade, um apelo fundado em nada. Ou seja, o salto em que se sustenta o próprio homem, é a metafísica!

\section{Referências}

DERRIDA, J. Margens da Filosofia. Campinas: Papirus, 1991.

HAAR, M. Heidegger e a essência do homem. Lisboa: Instituto Piaget, 1990.

HEIDEGGER, M. Que é Metafísica. In: . Conferências e escritos. São Paulo: Abril Cultural, 1979. . Kant y el problema de la metafísica. México DF: Fondo de Cultura Económica, 1954. . Sobre a essência da verdade. In: . Conferências e escritos. São Paulo: Abril Cultural, 1979. . Introdução à metafísica. Rio de Janeiro: Tempo Brasileiro, 1969. . Ser e tempo. v. 1. 14. ed. Petrópolis: Vozes, 2005. Ser e tempo. v. 2. 12. ed. Petrópolis: Vozes, 2005. INWOOD, M. Dicionário Heidegger. Rio de Janeiro: Jorge Zahar, 2002.

PASQUA, H. Introdução à leitura de Ser e Tempo de Martin Heidegger. Lisboa: Instituto Piaget, 1997.

STEIN, E. A questão do método na filosofia: um estudo do modelo heideggeriano. São Paulo: Duas Cidades, 1973.

Diferença e metafísica: ensaios sobre a desconstrução. Porto Alegre: EDIPUCRS, 2000.

${ }^{23}$ Cf.: HAAR, M. Heidegger e a essência do homem, p. 103-4. 